\title{
PENYUSUNAN DATABASE KONSTRUKSI REKLAME PAPAN BERBASIS INFORMASI GEOGRAFIS (Studi Kasus: Jalan Gejayan, Jalan Kaliurang dan Jalan Monjali)
}

\author{
Rizky Citra Islami ${ }^{1}$, Agus Nugroho ${ }^{2}$ \\ ${ }^{1,2}$ Departemen Teknik Sipil, Sekolah Vokasi Universitas Gadjah Mada \\ Email: ${ }^{1}$ rizkycitra@ugm.ac.id; ${ }^{2}$ mazgusnug@gmail.com
}

\begin{abstract}
One of the free trading impacts in Yogyakarta is increasing the number of promotion media in various forms, such as free standing signs, roof signs, wall signs, or suspended signs. As a tourism city that has a market share not only domestic but also international, its usual if the entrepreneur continuously compete for its product can be accepted by consumers. The used of advertisements in the main roads of Yogyakarta is one of the promotion stage. But in fact, the development of promotion media is almost not suitable with the procedures and even threaten the safety of road users. Its discrepancy happen because the lack of supervision from the government in Yogyakarta. In this study, researcher try to evaluate the effectiveness of billboard placement then assess its structure related to the safety of road users. Input of the structural assessments is using the dimension of billboard and its material. From the field survey, there are 58 units of billboards at Gejayan Street, 91 unit of billboards at Kaliurang Street, and 40 units of billboards at Monjali Street. The evaluation step detailed the pole construction and billboard side then done by structural assessment using SAP 2000. After the structural assessment is obtained, input the result of assessment into the geographic information system developed by ArcGIS 10.1. The benefit of using geographic information system is the data can be integrated from spatial map and additional information such as dimension, cross section image, and structural assessment. The various kinds of material is dominated by steel and iron with the range of dimension is about 0,4 until $20 \mathrm{~m}^{2}$. The structural analysis result showed that $43 \%$ of billboards, the pole didn't have structural reliability and the billboard's side is not suitable to buttress, so that they need to change their stucture. The research outcomes if its well applied, it can contribute as evaluation tools that used by government to discipline illegal advertisement billboards.
\end{abstract}

Keywords: billboards, structural assessment, geographic information system, road safety, evaluation 


\section{PENDAHULUAN}

Perkembangan kota terus berekspansi bersamaan dengan tumbuhnya perkembangan ekonomi dan teknologi. Indikator perkembangan suatu kota bukan hanya dapat diukur dengan menjulangnya gedung-gedung pencakar langit yang memiliki struktur kokoh atau infrastruktur transportasi yang berhasil menguraikan kemacetan, tetapi juga keseluruhan dinamika perkembangan yang dapat mewujudkan kota aman, tertib, teratur dan nyaman. Seiring dengan perkembangan pasar bebas, menuntut semakin meningkatnya persaingan ekonomi di berbagai bidang. Bidang perdagangan terus berlomba-lomba meningkatkan daya beli pasar melalui berbagai branding yang ditawarkan (Murtomo, 2007). Bidang industri mencoba memaknai pasar bebas dengan menerapkan teknologi tinggi yang dapat menekan penggunaan sumberdaya tetapi meningkatkan supply. Sedangkan bidang konstruksi sekarang tidak lagi hanya menangkap peluang pembangunan infrastruktur pemerintah tetapi juga mulai berekspansi untuk kebutuhan proyek business need dan customer request.

Yogyakarta sebagai salah satu kota besar di Indonesia terus berkembang dengan berbagai sektor pendukung perekonomiannya. Salah satu dampak pasar bebas yang terjadi di Yogyakarta adalah peningkatan media promosi dalam berbagai bentuk, seperti media reklame berdiri sendiri (free standing signs), melekat pada atap bangunan (roof signs), ditempatkan pada dinding (wall signs) ataupun yang digantung (suspended signs). Sebagai kota pariwisata yang memiliki market share bukan hanya wisatawan domestik tetapi juga mancanegara, wajar saja jika para pengusaha terus bersaing agar produknya dapat diterima oleh konsumen salah satunya melalui penggunaan reklame di jalan-jalan utama Yogyakarta. Jika meruntut pada Peraturan Daerah Kota Yogyakarta Nomor 2 Tahun 2015 tentang Penyelenggaraan Reklame pasal 15, sudah jelas disebutkan bahwa untuk mendapatkan izin penyelenggaraan reklame harus memenuhi syarat-syarat administrasi dan teknis (Pemda DIY, 2015). Bahkan peraturan daerah tersebut bukan hanya kebijakan yang menjabarkan secara general tetapi juga sudah mencakup teknis pelaksanaan.

Regulasi Pemerintah Kota Yogyakarta cukup jelas menjabarkan pengaturan tentang reklame mulai dari bentuk, ukuran, isi, zona penempatan bahkan zona khusus yang merupakan zona bebas dari penyelenggaraan reklame. Tetapi pada praktiknya di lapangan, perkembangan media promosi berbasis reklame hampir tidak sesuai dengan prosedur dan bahkan mungkin dapat mengancam keselamatan pengguna jalan. Adanya ketidaksesuaian tersebut adalah salah satu dampak dari kurangnya pengawasan pemerintah terhadap praktek penyelenggaraan reklame di Yogyakarta. Kebijakan yang baik, detail dan dapat mencangkup seluruh aspek 
apabila tidak mendapatkan porsi pengawasan yang sesuai juga tidak dapat optimal. Pengawasan pemerintah sebenarnya dapat dilakukan dengan mengikuti perkembangan teknologi yang ada (Rahmawati, 2013). Teknologi sistem informasi geografis yang terus berkembang saat ini dapat dijadikan alat pengawasan terhadap penyelenggaraan reklame. Penggabungan berbagai disiplin ilmu dapat dilakukan untuk optimalisasi konsep pengawasan yang dibutuhkan oleh Pemerintah Yogyakarta.

Konsep sistem informasi geografis yang merupakan cabang ilmu dari sistem informasi di bidang informatika dan spatial geografis dapat digabungkan dengan ilmu ketekniksipilan untuk mendukung konstruksi peletakan reklame dan pengaruhnya terhadap arus transportasi di lokasi (Septian, 2010). Bidang konstruksi mendukung penataan reklame agar memiliki standar keselamatan yang sesuai secara struktur peletakannya dan konstruksi bentuk papan reklame serta tiang penyangga. Sehingga pengawasan yang akan dilakukan juga dapat mendukung beberapa dinas terkait yang membidangi hal tersebut. Berdasarkan latar belakang tersebut, maka penelitian ini bertujuan untuk mengakomodir perkembangan papan reklame di Kota Yogyakarta. Hasil data manifest terhadap reklame papan tersebut kemudian dievaluasi terhadap keandalan struktur dan kemudian dituangkan dalam Sistem Informasi Geografis yang terintegrasi dengan data spasial. Oleh karena itu, penelitian ini dilakukan bertujuan memberikan solusi pengawasan berupa "Database Konstruksi Reklame Papan Berbasis Informasi Geografis” yang aplikatif.

\section{BAHAN DAN METODE PENELITIAN}

Penelitian ini menggunakan metode evaluatif dan development. Tahapan evaluatif adalah menganalisis hasil assessment kemampuan konstruksi reklame papan dan tahapan development adalah pengembangan sistem informasi berbasis spatial information. Tahapan penelitian tersaji dalam Gambar 1. 


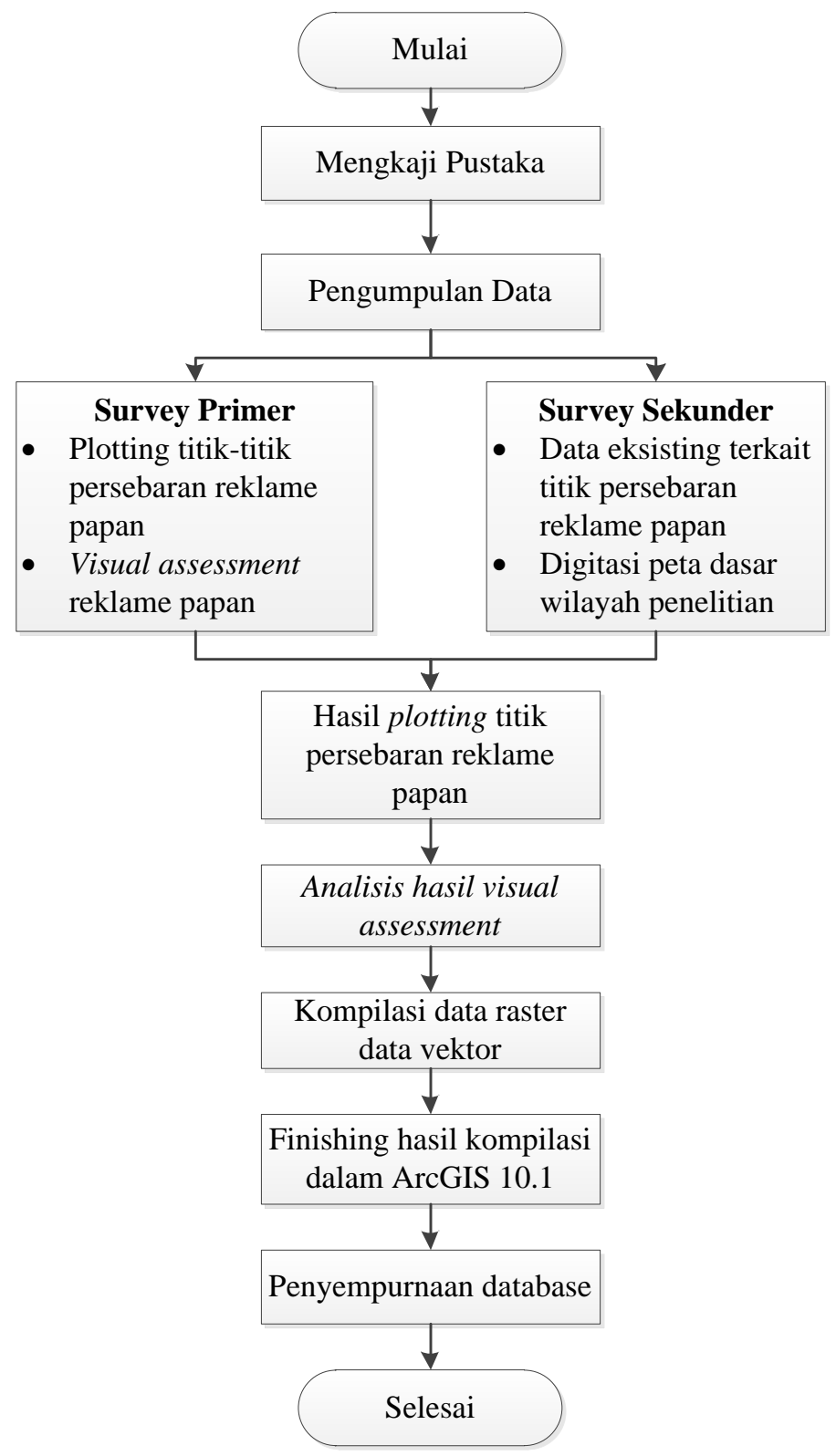

\section{Gambar 1. Diagram Alir Penelitian}

Tahapan pengumpulan data dilakukan dengan survey primer dan survey sekunder terhadap data yang menunjang input penelitian. Survey primer dilakukan dengan melibatkan 6 surveyor yang tersebar di 3 (tiga) jalan utama Yogyakarta meliputi Jalan Gejayan, Jalan Kaliurang, dan Jalan Monjali. Masing-masing dari surveyor dibekali alat survey yang meliputi:

1. Form survey

2. Kamera

3. Global Positioning System (GPS)

4. Laser distance meter

5. Alat tulis 
6. Rompi dan helm surveyor

Sedangkan untuk muatan form survey yang digunakan sebagai alat utama dalam survey primer terbagi atas 3 (tiga) unsur yaitu, jenis papan reklame, teknis pemasangan papan reklame, dan dimensi papan reklame. Pada penjabaran dimensi papan reklame, surveyor diharapkan mampu melakukan visual assessment terhadap setiap reklame papan yang ditemui di sepanjang ruas jalan. Selain itu, surveyor juga harus menentukan titik koordinat lokasi reklame papan berada dengan menggunakan Global Positioning System (GPS). Hal ini dimaksudkan untuk mendukung input dokumen dalam Sistem Informasi Geografis. Sedangkan secara rinci, isian form survey dimensi papan reklame terbagi atas beberapa unsur meliputi:

1. Tipe reklame
a. Komersial
b. Non-komersial

2. Dimensi papan
a. Panjang papan
b. Lebar papan
c. Tinggi papan
d. Material papan

3. Dimensi tiang
a. Jumlah tiang
b. Panjang tiang
c. Lebar tiang
d. Tinggi tiang
e. Material tiang

4. Tipe sambungan

5. Gambar sketsa

Berdasarkan input penelitian tersebut, maka variabel penelitian ini dapat dilakukan analisis dengan pembagian seperti pada Tabel 1.

\section{Tabel 1. Variabel Penelitian}

\begin{tabular}{clcc}
\hline No & Variabel Penelitian & $\begin{array}{c}\text { Analisis Evaluatif } \\
\text { (Visual Assessment \& SAP 2000) }\end{array}$ & $\begin{array}{c}\text { Analisis Development } \\
\text { (ArcGIS 10.1) }\end{array}$ \\
\hline 1 & Titik koordinat lokasi & - & $\checkmark$ \\
2 & Tipe reklame & $\checkmark$ & $\checkmark$ \\
3 & Dimensi papan & $\checkmark$ & $\checkmark$ \\
4 & Dimensi tiang & $\checkmark$ & $\checkmark$ \\
5 & Tipe sambungan & $\checkmark$ & $\checkmark$ \\
\hline
\end{tabular}




\begin{tabular}{cccc}
\hline No & Variabel Penelitian & $\begin{array}{c}\text { Analisis Evaluatif } \\
\text { (Visual Assessment \& SAP 2000) }\end{array}$ & $\begin{array}{c}\text { Analisis Development } \\
\text { (ArcGIS 10.1) }\end{array}$ \\
\hline 6 & Sketsa papan reklame & - & $\checkmark$ \\
\hline
\end{tabular}

Setelah dilakukan analisis data terkait dengan input hasil survey primer dan sekunder, maka dilakukan kompilasi hasil analisis dengan meruntut pada hasil visual assessment dan input database pada ArcGIS 10.1. Model pengaturan media reklame harus bersifat netral, perlu dipahami bahwa dalam aturan-aturan ada beberapa bagian yang sifatnya komersil dilarang dan lainnya diijinkan dan dirancang untuk keefektifan pelaksanaan administrasi. Aspek-aspek yang diatur meliputi:

1. Penggunaan peraturan

2. Metode perhitungan yang digunakan

3. Peraturan media reklame pada milik pribadi dengan dan tanpa ijin

4. Peraturan yang menyangkut ijin yang dibutuhkan

5. Peraturan atas desain, konstruksi dan pemeliharaan

6. Rencana induk kota

7. Peraturan atas media reklame yang berada dijalan umum

8. Tata informasi yang dikecualikan dan dilarang dalam peraturan

9. Prosedur perijinan secara umum termasuk ijin untuk membangun maupun memodifikasi media reklame serta perpanjangan ijin

10. Waktu berlakunya peraturan serta pelanggaran

11. Upaya pelaksanaan dan perbaikan
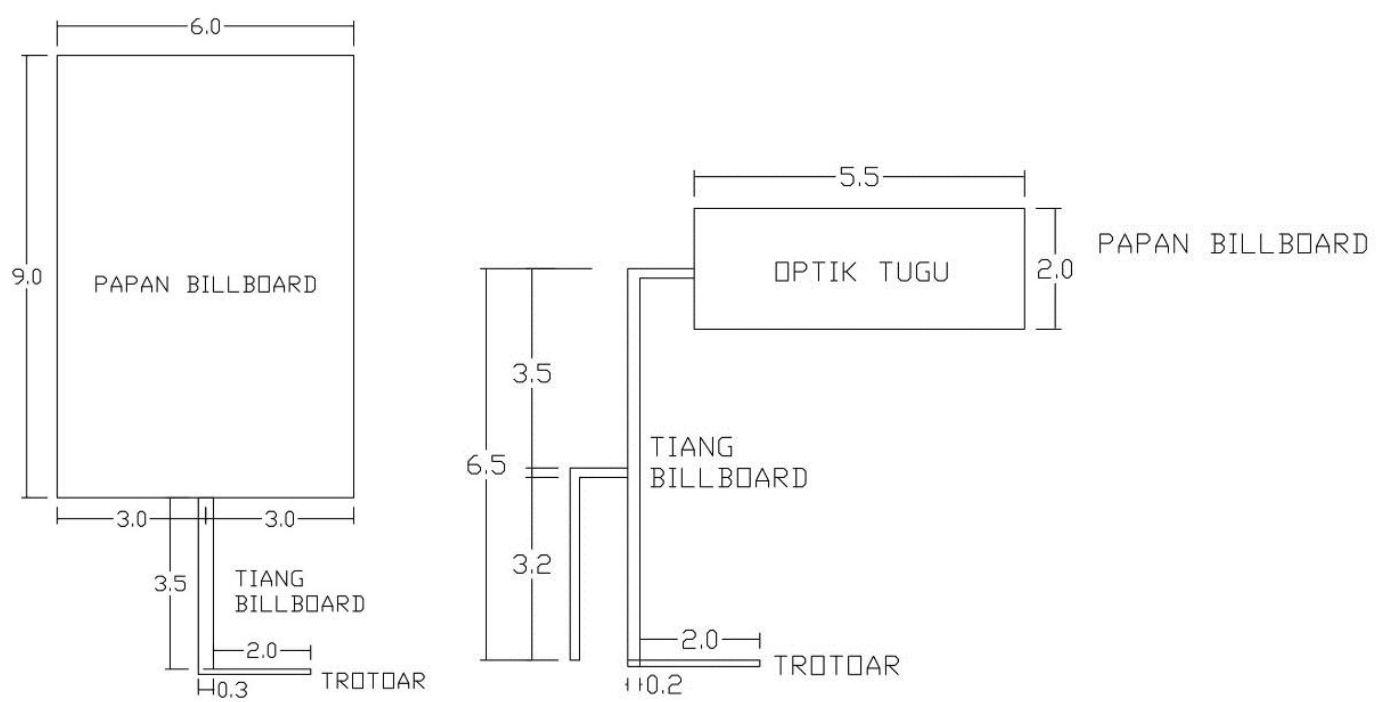

Gambar 2. Hasil Sketsa Reklame Papan 


\section{HASIL DAN PEMBAHASAN}

Pembahasan hasil penelitian akan dibagi berdasarkan variabel penelitian yang telah dilakukan menggunakan metode analisis evaluatif. Hasil dari penelitian ini memiliki beberapa tipe output, yaitu data kompilasi, peta, sketsa gambar dua dimensi (2D), hasil analisis struktur reklame papan, dan database Sistem Informasi Geografis.

\section{A. Titik Koordinat Lokasi}

Dalam menentukan titik koordinat lokasi, surveyor menggunakan Global Positioning System (GPS) untuk nantinya koordinat yang telah ada akan diolah menggunakan ArcGIS 10.1 untuk penyebaran lokasi. Berdasarkan persebaran lokasi papan reklame, maka didapatkan data jumlah persebaran yang tersaji dalam Gambar 3.

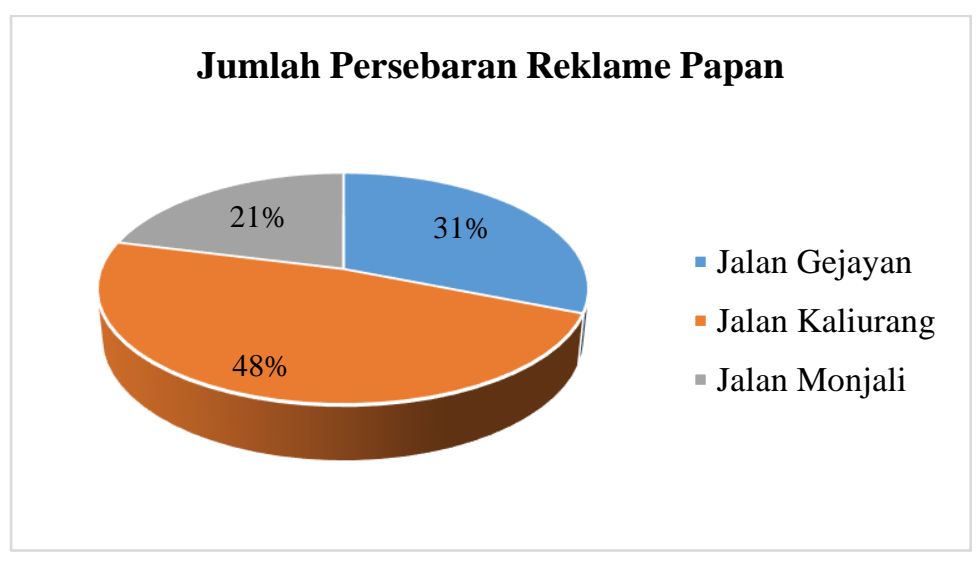

Gambar 3. Persebaran Lokasi Reklame Papan

Berdasarkan data persebaran reklame papan di jalan utama Yogyakarta, terlihat bahwa prosentase persebaran tertinggi berada di Jalan Kaliurang. Jalan Kaliurang merupakan salah satu pusat sarana perdagangan di sekitar area kampus Universitas Gadjah Mada. Guna lahan yang ada di area tersebut juga didominiasi oleh sarana perdagangan dan perumahan. Sehingga dalam pembuatan peta persebaran, masing-masing area dibagi atas beberapa zona meliputi, Jalan Gejayan terdapat 4 zona, Jalan Kaliurang 3 zona, dan Jalan Monjali 4 zona. Detail peta persebaran reklame papan adalah sebagai berikut: 
1) Jalan Gejayan

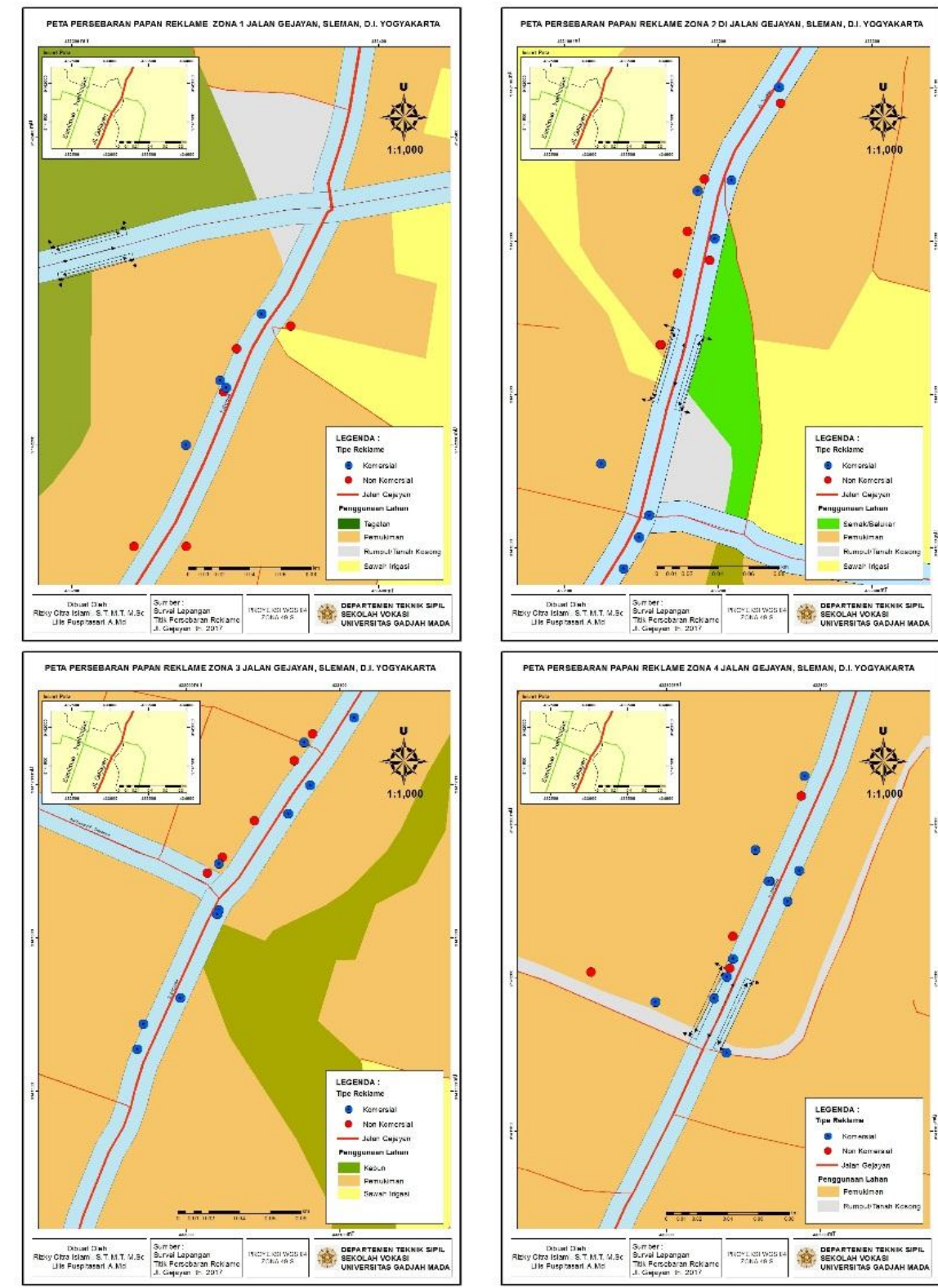

Gambar 4. Peta Persebaran Reklame Papan di Jalan Gejayan

Persebaran reklame papan di Jalan Gejayan yang tersaji dalam Gambar 4, terbagi atas 4 zona dimulai dari titik reklame di kawasan utara yaitu perbatasan Ring Road Utara hingga Selokan Mataram. Berdasarkan pembagian zona yang ada, persebaran reklame papan yang ada di Jalan Gejayan cukup tersebar merata pada masing-masing zona. Zona 1 memiliki persebaran terendah dengan jumlah 8 titik reklame papan dan pada zona 3 memiliki persebaran terbesar yaitu 15 titik reklame papan. Pada zona 3 merupakan daerah dengan guna lahan yang didominasi sarana perdagangan seperti restauran dan kios. Selain itu, hasil pengamatan didapati ada 10 titik lokasi reklame papan yang memiliki jarak sangat dekat antara satu dengan yang lain. Hal ini akan berdampak pada kekuatan tiang yang tidak optimal 
menopang papan reklame yang ada. Sedangkan dari segi keselamatan pengendara kendaraan, hal tersebut akan berpengaruh pada jarak pandang pengendara yang terbatas karena adanya penumpukan reklame papan pada titik lokasi yang berdekatan.

2) Jalan Kaliurang
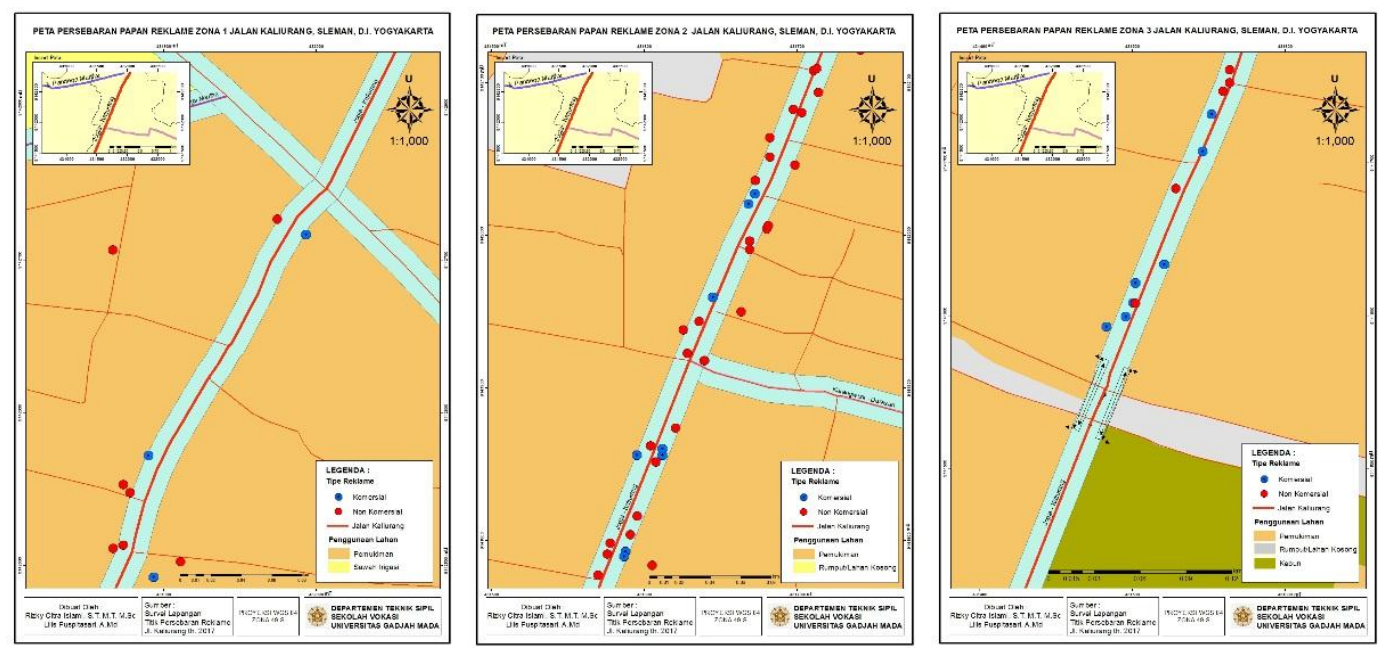

Gambar 5. Peta Persebaran Reklame Papan di Jalan Kaliurang

Persebaran reklame papan pada Jalan Kaliurang terbagi atas 3 zona yang setiap zona didominasi oleh guna lahan permukiman. Sama halnya dengan lokasi penelitian yang lain, titik mulai berada di Ring Road Utara dan diakhir di Selokan Mataram. Pada Jalan Kaliurang terlihat bahwa persebaran reklame papan tidak merata. Pada zona 1 seperti terlihat pada Gambar 5. bahwa reklame papan memiliki jarak yang cukup teratur dan tidak tumpang tindih. Sedangkan pada zona 2, persebaran reklame papan sangat masif dan pada beberapa titik terdapat penumpukan. Berdasarkan pembagian zona yang ada, zona 1 memiliki persebaran titik reklame papan yang paling rendah yaitu 10 titik. Persebaran tertinggi adalah pada zona 2 yaitu 36 titik. Tingkat efektivitas penempatan reklame papan di Jalan Kaliurang memang kurang diperhatikan, sehingga terdapat 28 titik reklame papan yang saling tumpang tindih satu dengan lainnya. 
3) Jalan Monjali
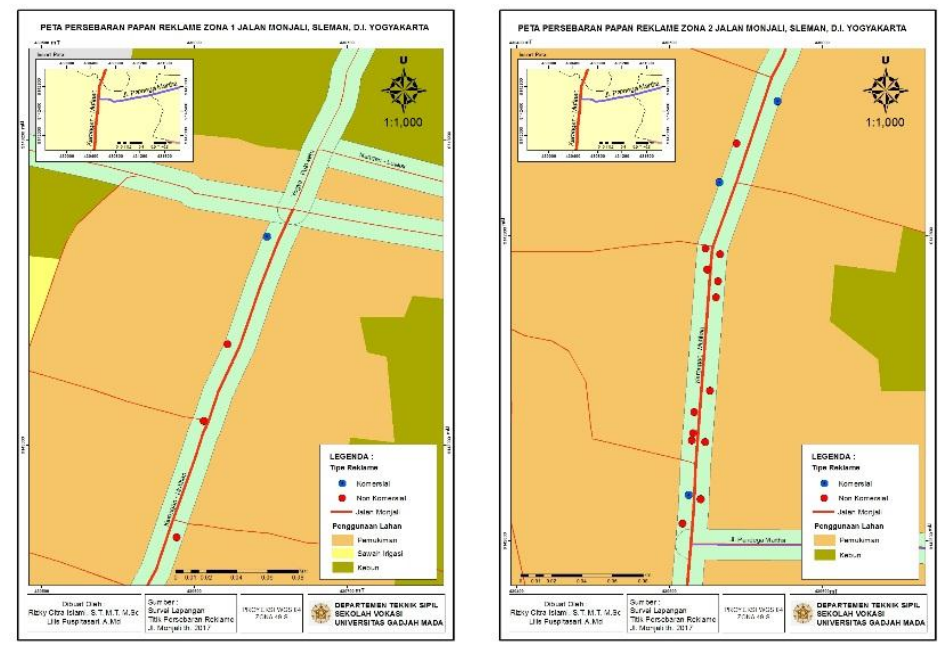

Gambar 6a. Peta Persebaran Reklame Papan di Jalan Monjali

Pada lokasi penelitian Jalan Monjali terbagi atas 4 zona yang memiliki karakteristik berbeda dengan dua wilayah lainnya. Persebaran reklame papan di wilayah Jalan Monjali yang tersaji dalam Gambar 6 a dan 6 b cukup teratur dan hanya terdapat 40 titik lokasi. Hal ini juga dipengaruhi oleh guna lahan yang tidak terlalu banyak didominasi sarana perdagangan. Titik persebaran lokasi reklame papan terbanyak berada di zona 2 dengan jumlah 16 titik dan terendah berada di zona 1 dengan jumlah 4 titik.
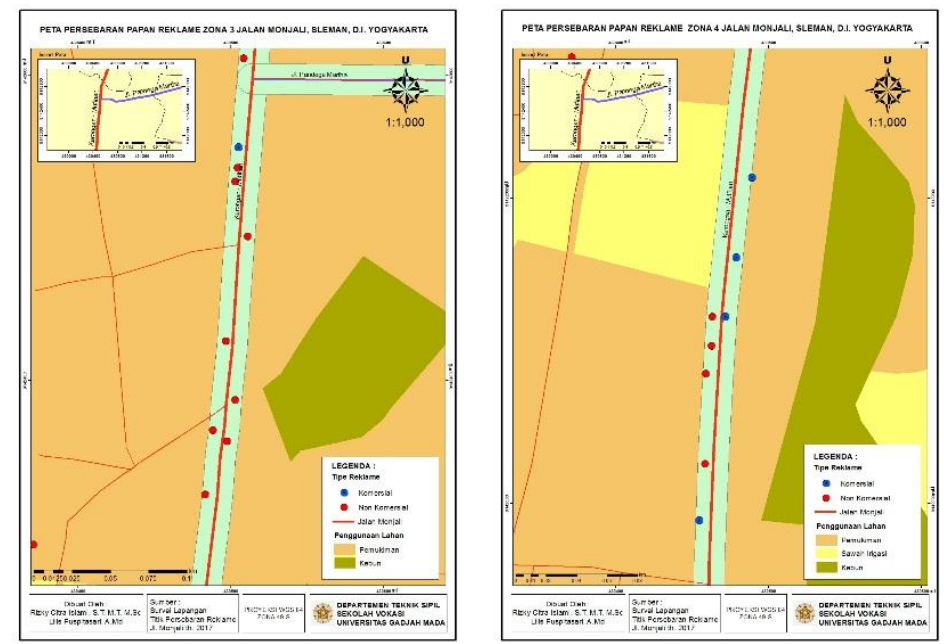

Gambar 6b. Peta Persebaran Reklame Papan di Jalan Monjali

\section{B. Tipe Reklame}

Tipe reklame dibagi atas isi pesan yang ada di reklame papan yaitu sebagai media komersial dan media non-komersial. Media komersial adalah reklame papan yang digunakan untuk kepentingan memperoleh keuntungan seperti, reklame penawaran barang. Sedangkan media non-komersial adalah reklame yang digunakan untuk kepentingan penyebaran 
informasi tanpa dasar keuntungan. Detail persebaran reklame papan berdasarkan tipe reklame tersaji dalam Gambar 7.

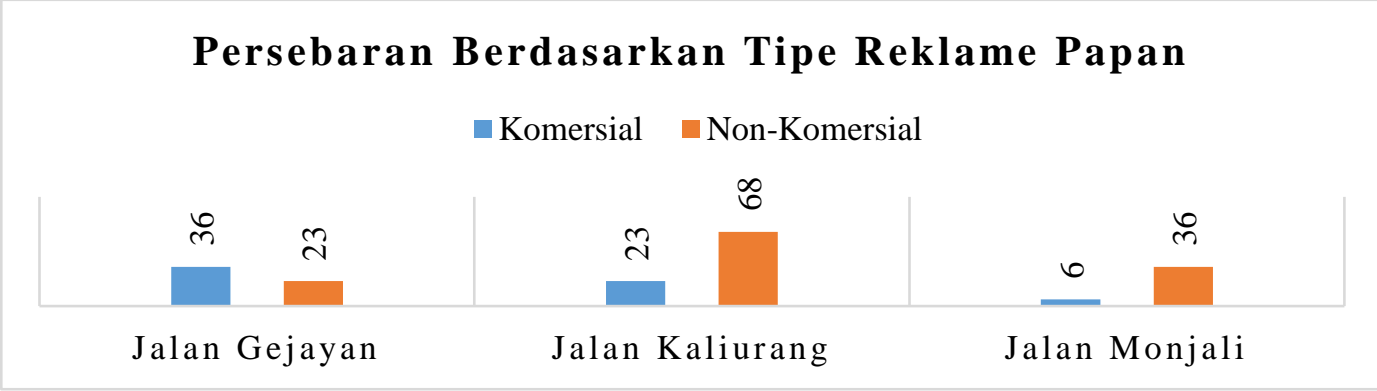

Gambar 7. Grafik Persebaran Reklame Papan Berdasarkan Tipe Reklame

Berdasarkan hasil penelitian diketahui tipe reklame papan didominasi oleh reklame non-komersial dengan jumlah 127 unit dan 65 unit merupakan reklame komersial. Dalam Gambar 8. adalah beberapa hasil photo mapping berdasarkan tipe reklame.
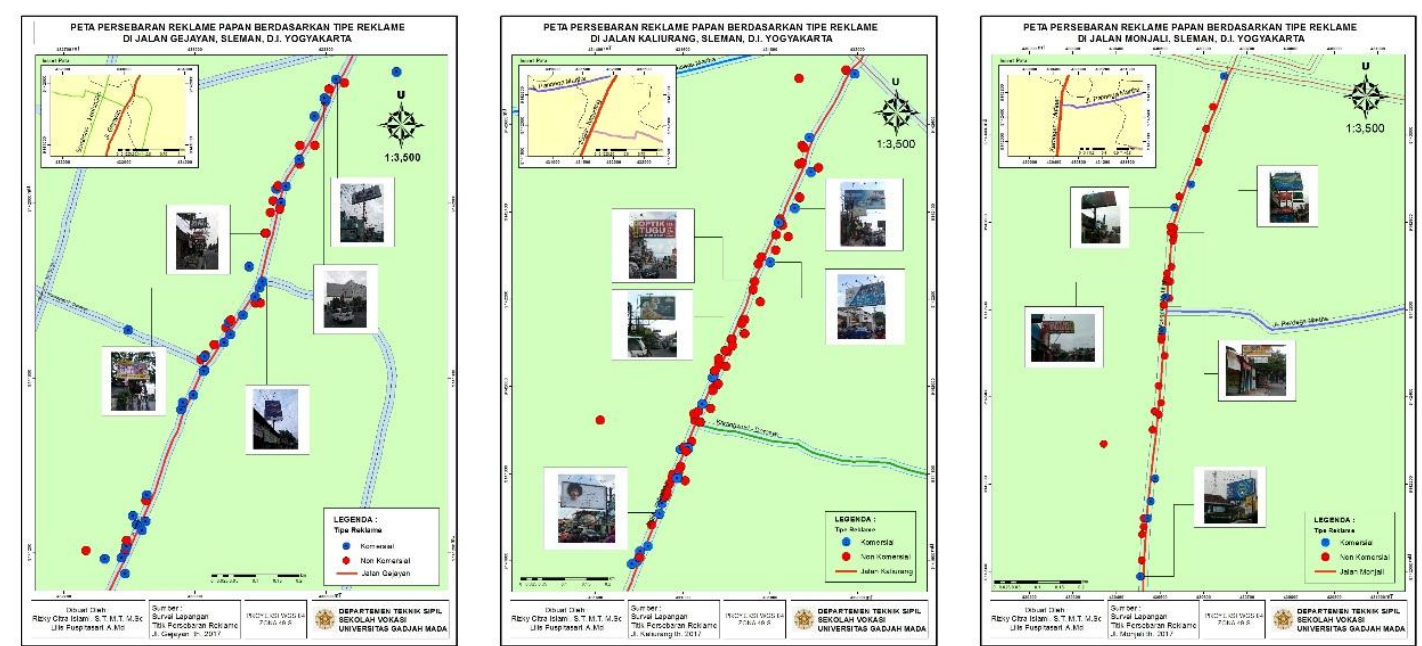

Gambar 8. Photo Mapping Persebaran Reklame Papan Berdasarkan Tipe Reklame

\section{Dimensi Papan}

Dimensi papan merupakan salah satu pertimbangan dalam membuat reklame papan, karena ukuran dimensi papan akan mempengaruhi dimensi tiang penyangganya. Selain itu, dimensi papan juga mempengaruhi konten iklan yang akan disampaikan. Berdasarkan hasil pengamatan, lebar dimensi papan dibagi atas beberapa kriteria tergantung lokasi yaitu, lebar 0,1 - 1,4 m dan 2,9 - $4 \mathrm{~m}$ untuk Jalan Gejayan, lebar 0,1 - 0,3 m, 0,4-0,6 m, serta 0,7 - 0,8 m untuk Jalan Kaliurang dan Jalan Monjali. Dimensi papan yang mendominasi adalah pada rentang 0,1 - 1,4 m untuk Jalan Gejayan dan 0,1 - 0,3 m untuk Jalan Kaliurang dan Jalan Monjali. Gambar 9 menunjukkan hasil peta persebaran reklame papan berdasarkan dimensi papan reklame. 

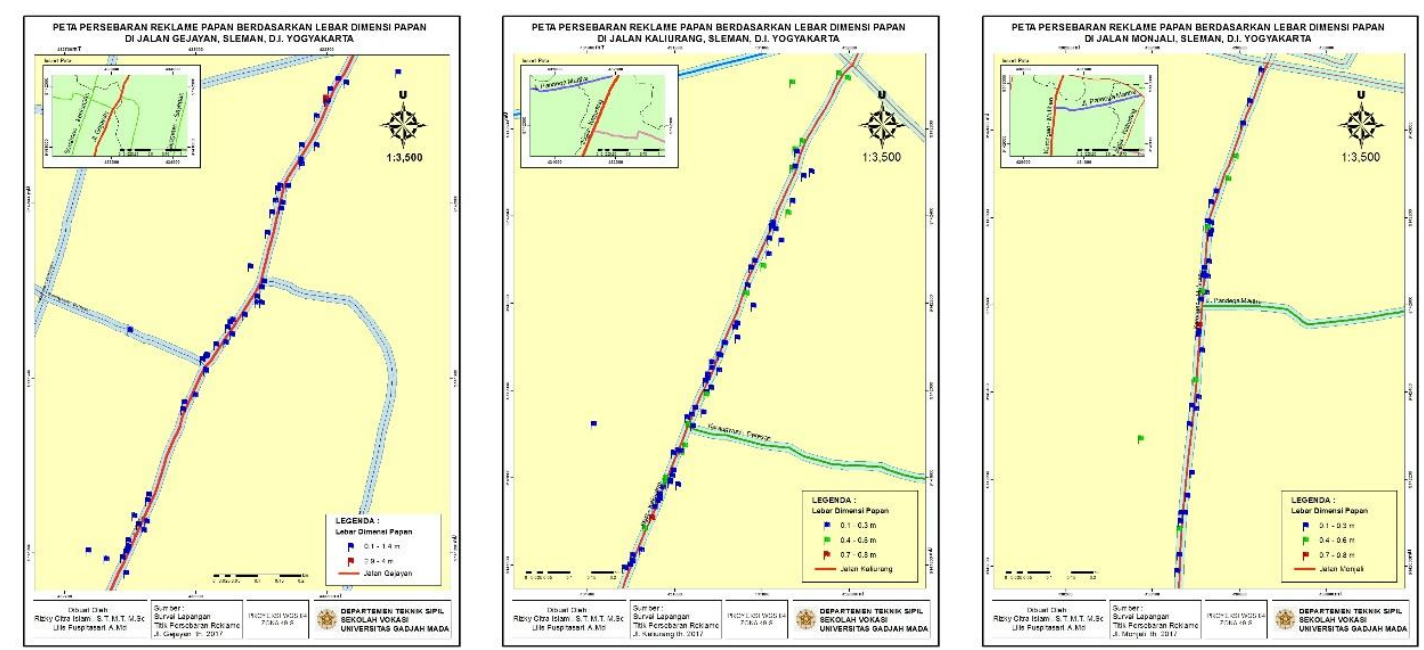

Gambar 9. Peta Persebaran Reklame Papan Berdasarkan Dimensi Papan Reklame

D. Dimensi Tiang

Dimensi tiang adalah salah satu kunci keandalan struktur sebuah reklame papan. Pada penelitian ini, karena dimensi lebar dimensi tiang yang berbeda untuk setiap lokasi penelitian, maka setiap lokasi akan memiliki pengelompokkan dimensi yang berbeda. Pada Jalan Gejayan dimensi tiang terbagi atas 2 (dua) tipe yaitu denga lebar $0,1-0,7 \mathrm{~m}$ dan 1,5-2 $\mathrm{m}$, Jalan Kaliurang memiliki 3 (tiga) tipe yaitu $0,1-0,3 \mathrm{~m}, 0,4-0,6 \mathrm{~m}$, dan 0,7 - 0,8 m, sedangkan Jalan Monjali memiliki 2 (dua) tipe yaitu 0,1 $\mathrm{m}-0,2 \mathrm{~m}$ dan 0,3-0,4 $\mathrm{m}$. Gambar 10 menjelaskan peta persebaran reklame papan berdasarkan dimensi tiang reklame.
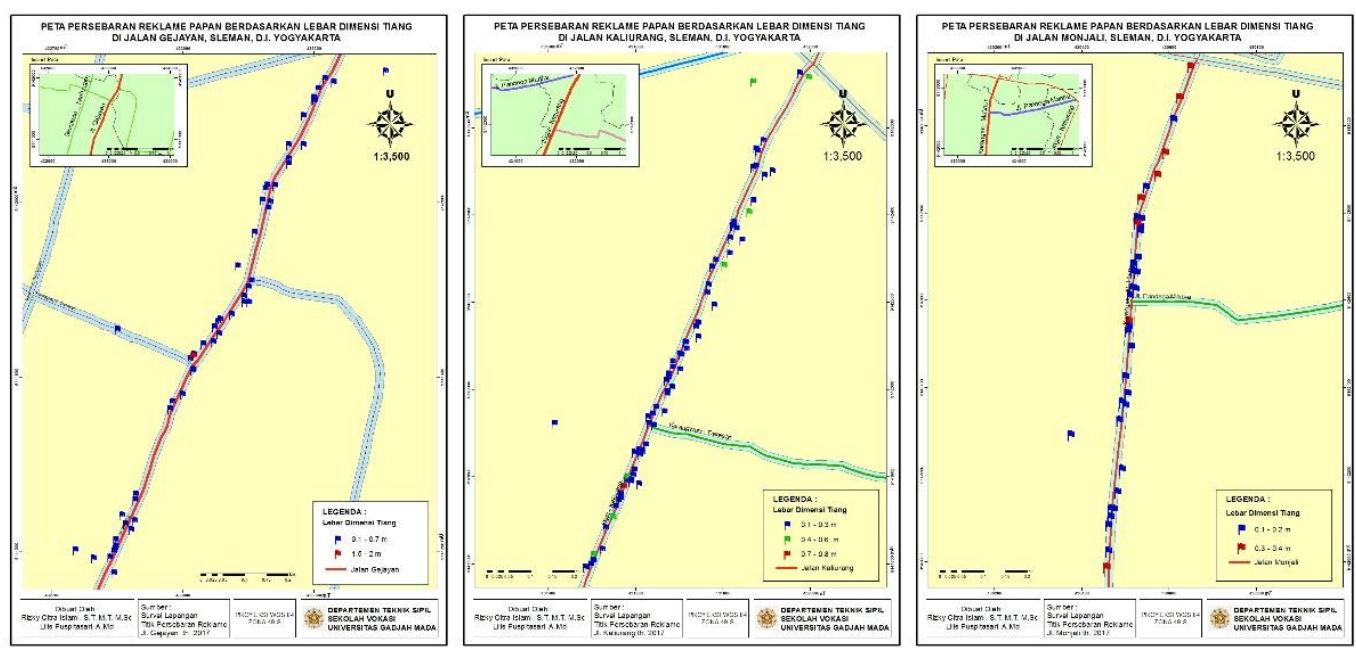

Gambar 10. Peta Persebaran Reklame Papan Berdasarkan Dimensi Tiang Reklame

\section{E. Tipe Sambungan}

Tipe sambungan yang digunakan pada reklame papan di semua wilayah penelitian adalah menggunakan las. Tipe sambungan menggunakan las ini adalah yang paling umum 
digunakan karena dapat digunakan pada media besi ataupun baja. Jumlah sambungan pada setiap reklame papan dapat dicermati pada hasil gambar dua dimensi (2D) di Gambar 11 berikut.

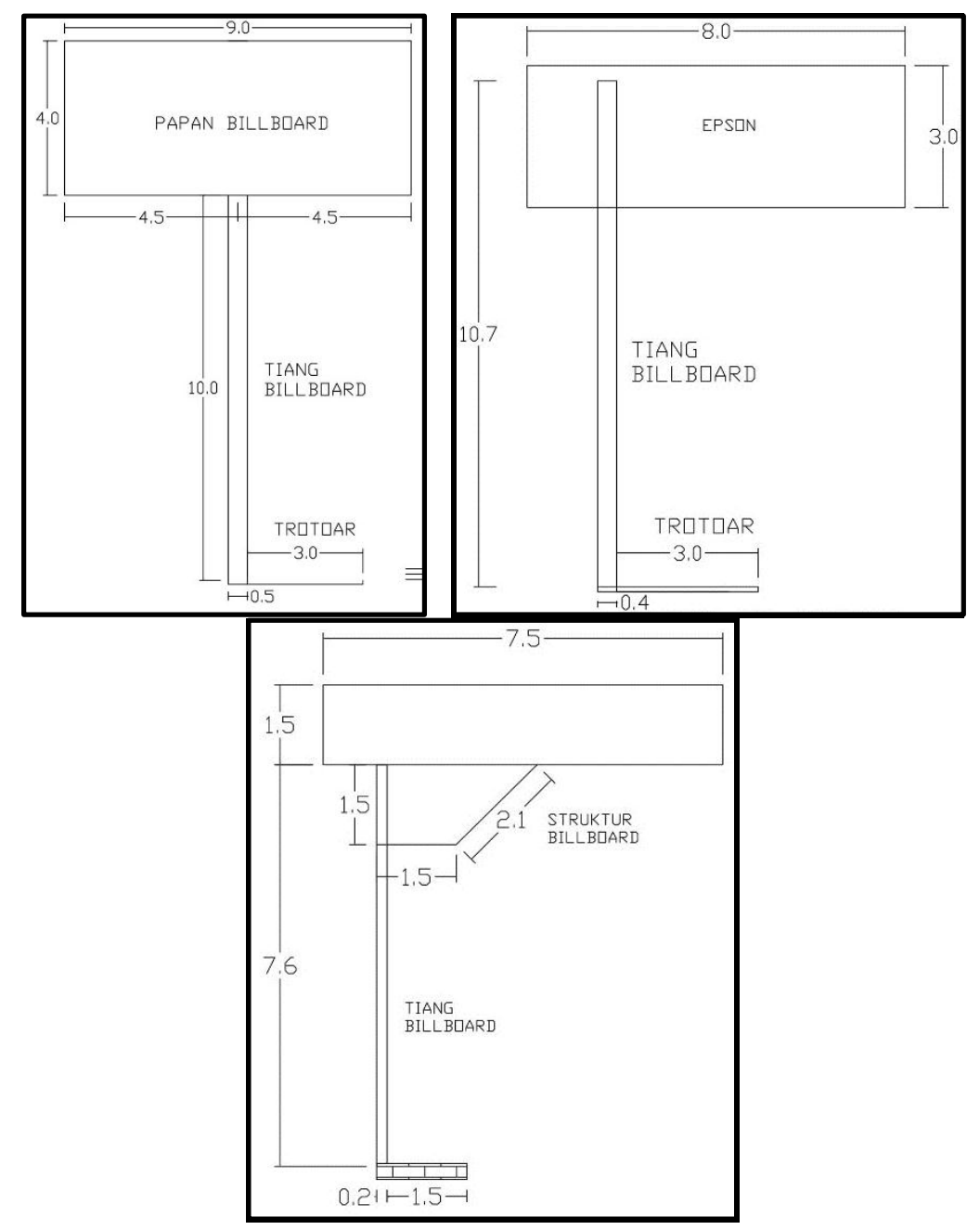

Gambar 11. Sketsa Dua Dimensi (2D) Reklame Papan

\section{KESIMPULAN}

Berdasarkan hasil penelitian yang telah dilakukan maka dapat ditarik kesimpulan bahwa penataan terhadap adanya reklame papan di Yogyakarta mutlak perlu untuk dilakukan. Karena berdasarkan pengamatan terhadap 3 (tiga) jalan utama di Yogyakarta menunjukkan bahwa walaupun regulasi terkait dengan penataan reklame telah ada tetapi pengawasannya masih sangat minim. Pemerintah dapat menggunakan Sistem Informasi Geografis untuk mendukung pengawasan terhadap keberadaan reklame papan di Yogyakarta. Adapun kesimpulan yang dapat ditarik dari penelitian ini adalah sebagai berikut: 
1. Total reklame papan yang ada di wilayah penelitian berjumlah 189 unit dengan persebaran 58 unit di Jalan Gejayan, 91 unit di Jalan Kaliurang, dan 40 unit di Jalan Monjali;

2. Berdasarkan hasil visual assessment, penataan reklame papan di Jalan Kaliurang kurang teratur daripada Jalan Gejayan dan Jalan Monjali, terlihat dari data penelitian yang didapat bahwa dari 91 unit reklame papan yang ada, 28 unit mengalami tumpang tindih dalam penataannya;

3. Sistem Informasi Geografis yang telah dibuat diharapkan dapat membantu Pemerintah Yogyakarta sebagai alat evaluasi efektivitas penataan reklame papan.

Selain itu, untuk penelitian selanjutnya diharapkan dapat dilakukan pada wilayah penelitian yang lebih luas dengan kompleksitas variabel penelitian yang lebih komprehensif. Peneliti dapat menambahkan tahapan penataan setelah diketahui bahwa pada wilayah penelitian tersebut penataan reklame papan tidak efektif.

\section{UCAPAN TERIMA KASIH}

Peneliti mengucapkan terima kasih terhadap pihak yang sudah membantu dalam kelancaran penelitian ini, terutama Departemen Teknik Sipil Sekolah Vokasi Universitas Gadjah Mada sebagai sumber dana penelitian. Selain itu, Tim Laboratorium Manajemen Konstruksi yang sudah membantu kelancaran penelitian ini mulai dari tahapan survey hingga pengolahan data.

\section{DAFTAR PUSTAKA}

Murtomo, Adji. 2007. Penataan Papan Reklame pada Penggal Jalan Hayam Wuruk Semarang. Jurnal Ilmiah Perancangan Kota dan Permukiman, Volume 6 No. 1 Maret 2007.

Rahmawati, Nurul Hilmy. (2013). Sistem Informasi Geografis Pengelolaan Reklame di Surabaya Berbasis Web. Jurnal Sains and Seni POMITS Vol. 2, No. 1, (2013) 2337-3520.

Septian, Haris. (2010). Pemilihan Lokasi Reklame dengan Menggunakan AHP-GIS di Kota Gresik. Jurnal Teknik Informatika, Politeknik Elektronika Negeri Surabaya.

Walikota Yogyakarta. 2015. Peraturan Daerah Kota Yogyakarta Nomor 2 Tahun 2015 tentang Penyelenggaraan Reklame. 